OPEN ACCESS

Edited by:

Peter Bede,

Trinity College Dublin, Ireland

Reviewed by:

Aude-Marie Grapperon Assistance Publique Hôpitaux de

Marseille, France

Timothée Lenglet,

Assistance Publique Hopitaux de

Paris, France

Pierre-Francois Pradat,

Hôpitaux Universitaires Pitie

Salpêtrière, France

*Correspondence:

Mamede de Carvalho mamedemg@mail.telepac.pt

Specialty section:

This article was submitted to

Neurodegeneration,

a section of the journal

Frontiers in Neurology

Received: 15 December 2018 Accepted: 04 February 2019 Published: 21 February 2019

Citation:

de Carvalho M, Swash M and Pinto S (2019) Diaphragmatic

Neurophysiology and Respiratory Markers in ALS. Front. Neurol. 10:143. doi: 10.3389/fneur.2019.00143

\section{Diaphragmatic Neurophysiology and Respiratory Markers in ALS}

\author{
Mamede de Carvalho ${ }^{1,2 *}$, Michael Swash ${ }^{1,3}$ and Susana Pinto ${ }^{1}$ \\ ${ }^{1}$ Instituto de Fisiologia-Instituto de Medicina Molecular, Faculdade de Medicina, Universidade de Lisboa, Lisbon, Portugal, \\ ${ }^{2}$ Department of Neurosciences and Mental Health, Hospital de Santa Maria-CHLN, Lisbon, Portugal, ${ }^{3}$ Barts and the London \\ School of Medicine, Queen Mary University of London, London, United Kingdom
}

The main reason for short survival in amyotrophic lateral sclerosis (ALS) is involvement of respiratory muscles. Severe compromise of diaphragmatic function due to marked loss of motor units causes poor inspiratory strength leading to symptomatic respiratory fatigue, and hypercapnia and hypoxemia, often firstly detected while sleeping supine. Weakness of expiratory muscles leads to cough weakness and poor bronchial clearance, increasing the risk of respiratory infection. Respiratory tests should therefore encompass inspiratory and expiratory function, and include measurements of blood gases during sleep. Non-volitional tests, such as phrenic nerve stimulation, are particularly convenient for investigating respiratory function in patients unable to perform standard respiratory function tests due to poor cooperation or facial weakness. However, SNIP is a sensitive test when patients with bulbar involvement are able to perform the necessary maneuvers. It is likely that central respiratory regulation is disturbed in some ALS patients, but its evaluation is more complex and not regularly implemented. Practical tests should incorporate tolerability, sensitivity, easy application for regular monitoring, and prognostic value. Impending respiratory failure can cause increased circulating inflammatory markers, but molecular assessment of respiratory distress requires further study. In future, home-monitoring of patients with accessible devices should be developed.

Keywords: amyotrophic lateral sclerosis, diaphragm physiology, progression, respiratory function tests, survival

\section{INTRODUCTION}

Respiratory insufficiency (RI) in ALS usually emerges in the late stage of disease progression, although it may sometimes be the presenting feature $(1,2)$. Respiratory complications, especially hypoventilation (2), reduced bronchial clearance and lung infection (3) account for the majority of deaths in ALS. Mild respiratory involvement causes fatigue in daily-life activities and disruption of sleep, with negative impact on quality of life $(4,5)$ and hypoxemia may impair cognitive function (6), especially important in a population with a lower cognitive reserve.

ALS affects both inspiratory and expiratory muscles, as well as upper airway muscles (7). Cough, an essential reflex for airway protection and clearance, depends on effective glottis closure and efficient expiratory muscle function. Bulbar muscle dysfunction impairs the former and, for this reason, cough effectiveness is not always correlated with expiratory muscle weakness (8). Weakness 
of pharyngeal and laryngeal muscles increases the risk of aspiration and lung infection. The latter is more critical when associated with marked cough deficiency. For active inspiration the diaphragm is the most important muscle, although other muscles function as accessory muscles of inspiration, e.g., sternocleidomastoid, scalenus, trapezius, external intercostal, pectoralis, and paraspinal muscles. These are particularly important when the diaphragm is weak and during exercise. Severe diaphragm weakness leads to hypoxemia and carbon dioxide retention, since the work capacity of these accessory muscles is not sufficient to compensate. Furthermore, these muscles are themselves progressively involved in the disease process (2). In ALS, the major reason for frank respiratory failure is involvement of the diaphragm (2). The phrenic nerve motor nuclei in the cervical spinal cord are located in a region early affected in ALS, shown by early morphometric changes in these neurons (9). Dyspnea in ALS is closely correlated with diaphragmatic dysfunction (10). Indeed, diaphragm weakness as assessed by the evoked response to transcutaneous phrenic nerve stimulation is predictive of hypoventilation (11) and survival (12). It is therefore relevant to assess the physiology of the diaphragm in people with ALS.

\section{DIAPHRAGM PHYSIOLOGY}

The diaphragm is the most important muscle of ventilation. It is a dome-shaped muscle that separates the thoracic and abdominal cavities. It has a musculo-fibrous structure, formed by a central non-contractile fibrous region, and contractile muscle fibers that radiate circumferentially from the central tendon to attach peripherally to the upper three lumbar vertebrae posteriorly (crural diaphragm) and onto the inner surface of the lower six ribs and costal cartilages antero-laterally (costal diaphragm). In humans, the diaphragm comprises approximately equal numbers of type I and type II fibers, but these muscle fibers are smaller than in the expiratory muscles. They have a rich capillary supply and are resistant to aging (13). Muscle spindles are present only in small numbers in the diaphragm (14), so muscle stretching does not much modulate phrenic neuronal excitability. Diaphragm is well adapted to the rhythmic continuous periodical inspiration of ventilation and to ocassional more forceful contractions, as in deep breaths and coughing. The mean diaphragm thickness at the point of functional residual capacity is $2.29 \pm 0.4 \mathrm{~mm}$, as measured by ultrasound (15) but is variable over its surface, and also dependent on body position. Diaphragmatic thickness can increase two-fold during full inspiration (16).

The motor innervation of the diaphragm is almost exclusively from the phrenic nerve (C3-5), which branches to innervate the entire muscle. Contraction of the diaphragm causes axial descent of the dome of the muscle, decreasing intrapleural pressure, and increassing intrabdominal pressure, thus exerting an expansive force on the lower thorax (17). This negative intrathoracic pressure causes an inflow of air to the lungs, promoting inspiration. The diaphragm is a very mobile muscle. With full inspiration it flattens, expanding the thorax down to the level of costal margin anteriorly, and during forced expiration it rises anteriorly to the level of the fourth or fifth intercostal space.

There is appreciable force reserve in the diaphragm. In humans the maximum transdiaphragmatic pressure is about 11 $\mathrm{kPa}$, which more than 10 times the value measured during eupnea (18). Indeed, normal respiration activates fatigue-resistant slowunits (19). However, coughing and sneezing are demanding maneuvers requiring very strong diaphragmatic contraction, close to $50 \%$ of the maximum transdiaphragmatic pressure, which implies activation of fast-fatigable motor units (19).

During calm breathing at rest expiration, unlike inspiration, is a passive phenomenon resulting from the relaxation of the inspiratory muscles and reduction of lung compliance. However, active forced expiration relies on recruitment of expiratory muscles, namely the internal intercostals and the abdominal ventro-lateral muscles (20). Generation of an adequate expiratory flux is needed for coughing, sneezing or vomiting. This is only possible with strong inspiration, closure of the glottis, and a sudden increase of intra-abdominal and intra-thoracic pressures. Effective peak cough flow (PCF) in healthy subjects exceeds 360$400 \mathrm{~L} / \mathrm{min}$ (21). Peak flow values $>160-200 \mathrm{~L} / \mathrm{min}$ are needed for effective mucus expectoration (22) and values above 250-270 $\mathrm{L} / \mathrm{min}$ are required to prevent aspiration pneumonia in patients with neuromuscular disorders (23).

The inspiratory pace-maker is located in the pre-Bötzinger Complex in the medulla (24). Its activity, both during inspiration and expiration, is modulated by inhibitory pre-motor neurons and by the Bötzinger Complex (18). Although expiration is a passive movement, active expiration involves a rostral generator, the retrotrapezoid nucleus (25). Synaptic drive to phrenic nerve nuclei is derived from pre-motor neurons located in the ipsilateral ventrolateral and dorsomedial medullary tracts, which respond to central chemoreceptors, sensitive to hypercapnia, and peripheral chemoreceptors, especially the carotid bodies, that are sensitive to hypoxemia. These premotor neurons are also sensitive to sleep-wake state modulation (18). Spinal interneurons can modulate phrenic motoneuronal activity, in particular via intercostal muscle afferents signaling strain of the chest wall (26). Voluntary control of breathing depends on fast, direct corticospinal inputs, which are also critical for respiratory control during speech (18). This pathway can be investigated by magnetic stimulation of cortical areas.

\section{ASSESSMENT OF RESPIRATORY DYSFUNCTION IN ALS}

In ALS inspiratory and expiratory muscles, as well as upper airway muscles are progressively involved. Studies of a possible dysfunctional central respiratory drive are few, but it is likely this could be affected in some patients with ALS (27). As such, different tests are necessary to provide a global view of the respiratory function of diseased subjects. The American (28) and the European (29) guidelines agree that a first respiratory evaluation should be made at the baseline clinical assessment and then periodically thereafter. Nevertheless, this must be adjusted individually, according to the rate of progression of 
the disease and when there are intercurrent events, such as infection, that may affect respiratory function. A summary of the available tests, their utility and limitations is provided in Table 1.

\section{Global Respiratory Evaluation}

Forced vital capacity (FVC) is a non-invasive respiratory test that has long been used in ALS. It assesses both the inspiratory and expiratory loops, requiring expiration done forcefully after a maximal inspiration, as opposed to slow vital capacity (SVC). This test is sensitive to change and predictive of hypoventilation and survival in ALS (30). The change of FVC is an adequate test to follow ALS patients $(30,31)$, since its decline rate tends to be linear ( $\sim 3.5 /$ month $)$, there is a high interpatient variability (32) but this rate is a strong predictor of survival (33). FVC can be an unreliable measure of ventilatory function in patients with bulbar involvement due to orofacial weakness, due to air leakage around the mouthpiece (2). FVC is more sensitive in detecting diaphragmatic weakness when performed in the supine position (34), but this position is often poorly tolerated due to secretions or to the extent of diaphragmatic weakness. In addition, it is not a very sensitive test to detect hypercapnia, since gas exchange is well maintained until FVC values are very low (35). SVC is easier to perform in patients with bulbar involvement, because the air is exhaled slowly, with less air-leakage around the mouthpiece. SVC has been preferred in a number of recent trials, as it is very strongly correlated with FVC (and with other respiratory tests such as Maximal Inspiratory Pressure and Maximal Expiratory Pressure), as well as with ALSFRS-R (36). It is a predictor of progression, the need for positive pressure ventilation, and survival in ALS $(37,38)$.

Maximal voluntary ventilation (MVV) assesses respiratory function on maintained efforts. The patient is asked to breathe in and out, through a mounthpiece, as deeply and quickly as possible during $12 \mathrm{~s}$, for at least two trials (39). The value is extrapolated for $1 \mathrm{~min}$. The test is demanding for ALS patients, due to their respiratory fatigue. It can be a sensitive measure of disease progression (30), but only in the early stages of the disease (39). This test is rarely performed in daily practice.

Nocturnal pulse oximetry (NPO) is a useful, non-invasive, inexpensive, and convenient method, which accesses respiratory function in a demanding state-when patients are lying and sleeping. It can be used individually or during polysonography, the latter allowing for clear characterization of possible central and/or peripheral apnea. NPO assesses percutaneous oxygen saturation (maximum, median, and minimum values), in relation with heart rate. Further, the pattern of the oxygen saturation curve overnight can be explored. NPO has been shown to be predictive of survival in ALS $(40,41)$. In addition, it can indicate central drive dysfunction in patients with normal respiratory muscles, a factor that is probably more common in spastic patients (42). NPO is a mandatory method to follow non-invasive ventilation adaptation in patients, which permits home-telemonitoring and distance alteration of ventilatory settings (43). Transcutaneous capnometry (PtcCO2) is a more modern approach to evaluate respiratory function in ALS and other neuromuscular disorders (44). PtcCO2 recordings show strong correlation with arterial measurements. A value higher than $49 \mathrm{mmHg}$ during $\geq 10 \%$ of the total recording time indicates respiratory insufficiency (44). Transcutaneous capnography has been strongly recommended for detection of nocturnal hypoventilation in patients with ALS (45). In patients on non-invasive ventilation, $\mathrm{PtcCO} 2$ can be helpful to monitor a proper ventilation, in particular to differenciate between hypoventilation and hypoxemia related to other reasons like as ventilation/perfusion mismatch, as well as in detecting hyperventilation (46). Both techniques have some limitations, for example they cannot discriminate other causes of sleep disturbances, such as obstructive sleep apnea, drug-effect, or associated lung disorder. Nonetheless they are very convenient as a screening method.

Blood gas measurements provide information about $\mathrm{CO}_{2}$ retention and hypoxemia when respiratory failure is severe. Because respiratory assessment is desiged to evaluate early changes, this test is not extensively used in ALS; however, it can provide relevant information for respiratory management in some patients.

Sleep studies have been investigated for a long time in ALS. In this disorder, reduction of the rapid eye movement (REM) sleep stage is typically observed, in particular when the diaphragm is markedly affected and accessory respiratory muscles are weak (47). It has been speculated that disturbed REM sleep might protect patients from hypoventilation (48). However, in patients with preserved diaphragmatic function, signs of sleep hypoventilation are observed as frequently in REM and non-REM phases (27), probably due to reduced respiratory drive (42). Arnulf et al. (48) found that ALS patients with upper motor neuron involvement to respiratory muscles tended to have abnormal REM sleep and poor prognosis. There is a strong link between severity of respiratory function impairment, poor quality of sleep, and daytime somnolence, in ALS (49).

\section{Evaluation of Inspiration}

Maximal inspiratory pressure (MIP) and nasal inspiratory pressure during a maximal sniff (SNIP) are inexpensive and noninvasive respiratory measures that access maximal inspiratory muscular strength, the first against a mouth occlusion and the second using a plug inserted in one nostril (50-52). In both, it is necessary to secure cooperation from patients to breath forcefully against a resistance. While 3 consistent measures are necessary to determine MIP (53), the number rises to 10 for SNIP, 5 in each nostril $(53,54)$, as the result improves with practice. Fatigue is a limiting factor for both techniques. MIP is more sensitive than FVC in detecting hypoventilation (55). However, its marked early decline (floor effect) limits its use in following patients and it is difficult to perform in patients with orofacial weakness (56) or with spasticity. SNIP is a sensitive tool especially suited for ALS patients with orofacial weakness. It is predictive of survival (57) and of the onset of significant hypoventilation in spinal-onset patients (5). There is some uncertainty about the best technical approach to test ALS patients in order to obtain reliable values (58). SNIP seems to depend more on diaphragm force and MIP 
TABLE 1 | A summary of the most relevant respiratory tests in ALS.

\begin{tabular}{|c|c|c|c|c|c|c|c|c|c|}
\hline & Tolerability & Simplicity & Reliability & Sensitivity & $\begin{array}{l}\text { Rate of } \\
\text { change }\end{array}$ & Technical difficulty & Cost $^{*}$ & $\begin{array}{c}\text { Ease for } \\
\text { monitoring }\end{array}$ & $\begin{array}{l}\text { Experience } \\
\text { in trials }\end{array}$ \\
\hline \multicolumn{10}{|l|}{ GLOBAL } \\
\hline SVC & ++ & +++ & ++ & + & ++ & $\begin{array}{l}\text { Volitional. Limited by } \\
\text { orofacial paresis and } \\
\text { dyscognition. }\end{array}$ & ++ & ++ & +++ \\
\hline MW & + & + & + & $+?$ & $+?$ & $\begin{array}{l}\text { Volitional. Needs motivation; } \\
\text { Limited by orofacial paresis, } \\
\text { fatigue, and dyscognition. }\end{array}$ & ++ & $+?$ & 0 \\
\hline NPO & +++ & +++ & +++ & ++ & + & $\begin{array}{l}\text { Limited by cold hands or } \\
\text { poor sleep. }\end{array}$ & + & +++ & 0 \\
\hline TCP & +++ & +++ & +++ & ++ & $+?$ & $\begin{array}{l}\text { Limited by cold hands and } \\
\text { poor sleep. }\end{array}$ & ++ & +++ & 0 \\
\hline MIP & + & + & ++ & +++ & +++ & $\begin{array}{l}\text { Volitional. Limited by } \\
\text { orofacial paresis, fatigue, } \\
\text { and dyscognition; early floor } \\
\text { effect. }\end{array}$ & ++ & + & 0 \\
\hline SNIP & ++ & ++ & ++ & $++?$ & ++ & $\begin{array}{l}\text { Volitional. Limited by } \\
\text { orofacial paresis and } \\
\text { dyscognition. }\end{array}$ & + & ++ & +++ \\
\hline Diaphragm US & +++ & +++ & +++ & $++?$ & ++ & Limited by dyscognition. & ++ & ++ & 0 \\
\hline Phrenic stimulation & + & ++ & ++ & + & ++ & $\begin{array}{l}\text { Limited by electrical } \\
\text { stimulation intolerance. }\end{array}$ & ++ & ++ & \\
\hline \multicolumn{10}{|c|}{ EXPIRATORY TESTS } \\
\hline PEF & ++ & ++ & ++ & $+?$ & ++ & $\begin{array}{l}\text { Volitional. Limited by } \\
\text { orofacial paresis and } \\
\text { dyscognition. }\end{array}$ & ++ & ++ & 0 \\
\hline \multicolumn{10}{|c|}{ CENTRAL DRIVE FUNCTION } \\
\hline P01 & ++ & + & + & $+?$ & $+?$ & $\begin{array}{l}\text { Volitional. Limited by } \\
\text { orofacial paresis, fatigue } \\
\text { and dyscognition. }\end{array}$ & ++ & + & 0 \\
\hline
\end{tabular}

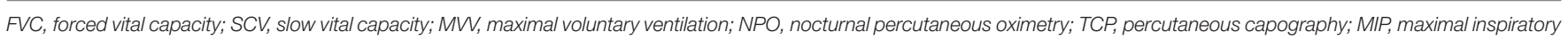
pressure; US, ultrasound; PEF, peak-expiratory flow; PCF, peak-cough flow; MEP, maximal expiratory pressure; P01, mouth occlusion pressure (100 ms).

${ }^{*}$ Cost (greater number of plus symbol means higher cost) was estimated taking into account equipament price and the requirement of a technician.

**ase for monitoring was estimated considering patient confort and technical complexity.

more on the sternocleidomastoid muscle power, making these tests complementary (59).

Transdiaphragmatic pressure (Pdi) can be assessed by inserting balloon catheters in the stomach and mid-esophagus and measuring the differential pressure during active maximal inspiration (60) or following stimulation of the phrenic nerve (61). This is an uncomfortable test that is not suited to clinical application.

Diaphragmatic ultrasound (US) is a non-invasive technique that assesses diaphramatic dynamics, and measures the muscle thickness at tidal volume and on maximal inspiration, as well as the ratio between baseline and maximal inspiration, useful measures to detect diaphragm involvement $(62,63)$. Significant correlations have been found between these measurements and FVC, SNIP, and the amplitude of the motor response of the phrenic nerve (62-64). However, ultrasound studies are less sensitive than phrenic nerve motor responses in assessing early deterioration of the diaphragm in ALS (65).

Phrenic nerve stimulation by percutaneous electrical or magnetic stimulation in the neck to elicit diaphragm motor responses is an objective, non-volitional test $(66,67)$ that can 




FIGURE 1 | Represents the progressive parallel decline of FVC and phrenic nerve compound muscle action potential amplitude in an ALS patient with slow progression. Values were normalized to $100 \%$ of normal at first assessment. This figure is simply for representative purposes and not intended to present research findings.

be used to assess the number of functional motor units in the diaphragm (68). Abnormal amplitude (or area) of the motor response has good predictive value for hypoventilation in both bulbar- and spinal-onset patients, and is correlated to FVC (11). This technique is useful in patients with marked facial weakness or in those unable to cooperate, for example those with fronto-temporal dementia. The amplitude of the motor response declines significantly over 3-6 months, and correlates with FVC and SNIP change (69); it is predictive of survival in ALS (12). Figure 1 represents the progressive and parallel decline of FVC and phrenic nerve compound muscle action potential in an ALS patient.

\section{Evaluation of Expiration}

The efficiency of the expiratory muscles can be easily addressed by evaluating the peak expiratory flow (PEF) and the peak cough flow (PCF), and maximal expiratory pressure (MEP) evaluates the strength of these muscles. These three volitional tests are simple to perform, inexpensive, and non-invasive. Although they measure expiratory muscle function, they depend on central motor control as well as on the efficiency of the inspiratory muscles. Abnormally reduced values indicate inability to expel bronchial secretions, leading to a high risk of respiratory infections (39), leading to increased morbility and mortality (70). MEP values are measured by asking the patient to exhale forcefully against an ocluded mouthpiece. Abnormal values are common in ALS patients $(8,71)$, and correlate with inspiratory involvement. PEF and PCF use peak flow meters, coupled with a face mask for PCF testing, and assess the ability to exhale forcefully after a maximal inspiration $(72,73)$ and to cough after a submaximal inspiration (60). Coughing can also be assessed by the gastric pressure generated during a maximal cough, which is a sensitive method to assess expiratory muscle strength, but this is an invasive and poorly tolerated test (74).

\section{Evaluation of the Central Respiratory Drive}

Both NPO and sleep studies can detect respiratory center dysfunction, in particular in patients with normal respiratory muscles in whom nocturnal hypoventilation is detected without obstructive apnea (27). Inspiratory mouth occlusion pressure at $100 \mathrm{~ms}$ during quiet breathing (P0.1) is considered an indicator of respiratory drive. Spastic patients with normal diaphragm function tend to show abnormal P0.1/FVC values, associated with a poor prognosis for survival (42). P01 values are similar in bulbar and spinal-onset patients at presentation (56), suggesting that impaired central drive does not depend on the region of onset. The observation of "respiratory apraxia" in ALS patients highlights the complexity and importance of the cortical control of respiration and its potential involvement in ALS (75).

\section{CONCLUSIONS}

There are many tests available to evaluate different features of respiratory function in ALS. In general, most centers follow a conventional approach by evaluating SVC and FVC, which are are often applied in clinical trials. Patients may also be asked to undergo maximal pressure measurements, expiratory peak flows and nocturnal oximetry, sometimes associated with EEG recordings. Less commonly, diaphgram ultrasound or phenic nerve motor responses to percutaneous cervical electrical stimulation of the nerve are tested. Percutaneous capnography is emerging as a relevant technique. Disparity in patients'tolerability and technical limitations would recommend to apply more than one single test to assess respiratory function in ALS patients. 
A future study combining most of these tests in a single set of ALS patients would provide more information about diagnostic accuracy, sensitivity, realibility, and convenience for monitoring disease progression. This would have major potential implications in clinical trials, since changing the rate of respiratory decline is critical for improving survival and functional capability.

The identification of a molecular marker of respiratory impairment in ALS would be a convenient and valuable test. Some research indicates that respiratory insufficiency can precipitate an inflammatory response $(76,77)$, and this is a new avenue yet to be fully explored. User-friendly devices for inhome respiratory evaluation is another future step. New tests to directly evaluate strength of respiratory muscles will require a better understanding of their physiology.

\section{REFERENCES}

1. de Carvalho M, Matias T, Evangelista T, Pinto A, Sales Luís ML. Motor neuron disease presenting with respiratory failure. J Neurol Sci. (1996) 139:117-22. doi: 10.1016/0022-510X(96)00089-5

2. Pinto S, de Carvalho M. Breathing new life into treatment advances for respiratory failure in amyotrophic lateral sclerosis patients. Neurodegener Dis Manag. (2014) 4:83-102. doi: 10.2217/nmt.13.74

3. Corcia P, Pradat PF, Salachas F, Bruneteau G, Le Forestier N, Seilhean D, et al. Causes of death in a post-mortem series of ALS patients. Amyotroph Lateral Scler. (2008) 9:59-62. doi: 10.1080/17482960701656940

4. Lyall RA, Donaldson N, Fleming T, Wood C, Newsom-Davis I, Polkey MI, et al. A prospective study of quality of life in ALS patients treated with noninvasive ventilation. Neurol (2001) 57:153-6. doi: 10.1212/WNL.57.1.153

5. Lyall RA, Donaldson N, Polkey MI, Leigh PN, Moxham J. Respiratory muscle strength and ventilatory failure in amyotrophic lateral sclerosis. Brain (2001) 124:2000-13. doi: 10.1093/brain/124.10.2000

6. Newsom-Davis IC, Lyall RA, Leigh PN, Moxham J, Goldstein LH. The effect of non-invasive positive pressure ventilation (NIPPV) on cognitive function in amyotrophic lateral sclerosis (ALS): a prospective study. J Neurol Neurosurg Psychiatry (2001) 71:482-7. doi: 10.1136/jnnp.71.4.482

7. Benditt JO. Respiratory complications of amyotrophic lateral sclerosis. Semin Repir Crit Care Med. (2002) 23:239-47. doi: 10.1055/s-2002-33032

8. Polkey MI, Lyall RA, Green M, Leigh NP, Moxham J. Expiratory muscle function in amyotrophic lateral sclerosis. Am J Respir Crit Care Med. (1998) 158:734-41. doi: 10.1164/ajrccm.158.3.9710072

9. Bradley WG, Good P, Rasool CG, Adelman LS. Morphometric and biochemical studies of peripheral nerves in amyotrophic lateral sclerosis. Ann Neurol. (1983) 14:267-77. doi: 10.1002/ana.410140304

10. Similowski T, Attali V, Bensimon G, Salachas F, Mehiri S, Arnulf I, et al. Diaphragmatic dysfunction and dyspnoea in amyotrophic lateral sclerosis. Eur Respir J. (2000) 15:332-7. doi: 10.1034/j.1399-3003.2000. 15b19.x

11. Pinto S, Geraldes R, Vaz N, Pinto A, de Carvalho M. Changes of the phrenic nerve motor response in amyotrophic lateral sclerosis: longitudinal study. Clin Neurophysiol. (2009) 120:2082-5. doi: 10.1016/j.clinph.2009. 08.025

12. Pinto S, Pinto A, de Carvalho M. Phrenic nerve studies predict survival in amyotrophic lateral sclerosis. Clin Neurophysiol. (2012) 123:2454-9. doi: 10.1016/j.clinph.2012.05.012

13. Mizuno M. Human respiratory muscles: fibre morphology and capillary supply. Eur Respir J. (1991) 4:587-601.

14. Duron B, Jung-Caillol MC, Marlot D. Myelinated nerve fiber supply and muscle spindles in the respiratory muscles of cat: quantitative study. Anat Embryol. (1978) 152:171-92. doi: 10.1007/BF00315923

15. Dhungana A, Khilnani G, Hadda V, Guleria R. Reproducibility of diaphragm thickness measurements by ultrasonography in patients

\section{AUTHOR CONTRIBUTIONS}

All authors listed have made a substantial, direct and intellectual contribution to the work, and approved it for publication.

\section{FUNDING}

This research was supported by UID/BIM/50005/2019, project funded by Fundação para a Ciência e a Tecnologia (FCT)/Ministério da Ciência, Tecnologia e Ensino Superior (MCTES) through Fundos do Orçamento de Estado.

\section{ACKNOWLEDGMENTS}

We are grateful to Mariana Pereira for preparing the figure.

on mechanical ventilation. World J Crit Care Med. (2017) 6:185-9. doi: 10.5492/wjccm.v6.i4.185

16. Hellyer NJ, Andreas NM, Bernstetter AS, Cieslak KR, Donahue GF, Steiner EA, et al. Comparison of diaphragm thickness measurements among postures via ultrasound imaging. $P M R$ (2017) 9:21-5. doi: 10.1016/j.pmrj.2016.06.001

17. Roussos C, Macklem PT. The respiratory muscles. N Engl J Med. (1982) 307:786-97. doi: 10.1056/NEJM198209233071304

18. Fogarty MJ, Mantilla CB, Sieck GC. Breathing: motor control of diaphragm muscle. Physiology (2018) 33:113-26. doi: 10.1152/physiol.00002.2018

19. Mantilla CB, Seven YB, Zhan WZ, Sieck GC. Diaphragm motor unit recruitment in rats. Respir Physiol Neurobiol. (2010) 173:153-6. doi: 10.1016/j.resp.2010.07.001

20. Ewing JM, Griscom NT, Wohl MEB. The effect of the absence of abdominal muscles on pulmonary function and exercise. Am J Resp Crit Care Med. (1996) 153:1314-21. doi: 10.1164/ajrccm.153.4.8616560

21. Gregg I, Nunn AJ. Peak expiratory flow in normal subjects. Br Med J. (1973) 3:282-4. doi: 10.1136/bmj.3.5874.282

22. Chatwin M, Ross E, Hart N, Nickol AH, Polkey MI, Simonds AK. Cough augmentation with mechanical insufflation/exsufflation in patients with neuromuscular weakness. Eur Respir J. (2003) 21:502-8. doi: 10.1183/09031936.03.00048102

23. Kang SW, Bach JR. Maximum insufflation capacity: vital capacity and cough flows in neuromuscular disease. Am J Phys Med Rehabil. (2000) 79:222-7. doi: 10.1097/00002060-200005000-00002

24. Richter DW. Generation and maintenance of the respiratory rhythm. J Exp Biol. (1982) 100:93-107.

25. Koizumi H, Koshiya N, Chia JX, Cao F, Nugent J, Zhang R, et al. Structural-functional properties of identified excitatory and inhibitory interneurons within pre-Botzinger complex respiratory microcircuits. J Neurosci. (2013) 33:2994-3009. doi: 10.1523/JNEUROSCI.4427-12. 2013

26. Bellingham MC. Synaptic inhibition of cat phrenic motor neurons by internal intercostal nerve stimulation. J Neurophysiol. (1999) 82:1224-32. doi: 10.1152/jn.1999.82.3.1224

27. Atalaia A, de Carvalho M, Evangelista T, Pinto A. Sleep characteristics of amyotrophic lateral sclerosis in patients with preserved diaphragmatic function. Amyotroph Lateral Scler. (2007) 8:101-5. doi: 10.1080/17482960601029883

28. Miller RG, Jackson CE, Kasarskis EJ, England JD, Forshew D, Johnston $\mathrm{W}$, et al. Practice parameter update: the care of the patient with amyotrophic lateral sclerosis: drug, nutritional, and respiratory therapies (an evidence-based review) Report of the Quality Standards Subcommittee of the American Academy of Neurology. Neurology (1999) 73:1218-26. doi: 10.1212/WNL.0b013e3181bc0141

29. Andersen PM, Abrahams S, Borasio GD, de Carvalho M, Chio A, Van Damme $\mathrm{P}$, et al. EFNS guidelines on the clinical management of amyotrophic lateral sclerosis (MALS)-revised report of an EFNS Task Force on Diagnosis and 
Management of Amyotrophic Lateral Sclerosis. Eur J Neurol. (2012) 19:36075. doi: $10.1111 / \mathrm{j} .1468-1331.2011 .03501 . x$

30. Fallat RJ, Jewitt B, Bass M, Kamm B, Norris F. Spirometry in amyotrophic lateral sclerosis. Arch Neurol. (1979) 36:74-80. doi: 10.1001/archneur.1979.00500380044004

31. Czaplinski A, Yen AA, Appel SH. Forced vital capacity (FVC) as an indicator of survival and disease progression in an ALS clinic population. $J$ Neurol Neurosurg Psychiatry (2006) 77:390-2. doi: 10.1136/jnnp.2005.072660

32. Schiffman PL, Belsh JM. Pulmonary function at diagnosis of amyotrophic lateral sclerosis: rate of deterioration. Chest (1993) 103:508-13. doi: 10.1378/chest.103.2.508

33. Magnus T, Beck M, Giess R, Puls I, Naumann M, Toyka KV. Disease progression in amyotrophic lateral sclerosis: predictors of survival. Muscle Nerve (2002) 25:709-14. doi: 10.1002/mus.10090

34. Lechtzin N, Wiener CM, Shade DM, Clawson L, Diette GB. Spirometry in the supine position improves the detection of diaphragmatic weakness in patients with amyotrophic lateral sclerosis. Chest (2002) 121:436-42. doi: $10.1378 /$ chest.121.2.436

35. Kaplan LM, Hollander D. Respiratory dysfunction in amyotrophic lateral sclerosis. Clin Chest Med. (1994) 15:675-81.

36. Pinto S, de Carvalho M. Correlation between Forced Vital Capacity and Slow Vital Capacity for the assessment of respiratory involvement in Amyotrophic Lateral Sclerosis: a prospective study. Amyotroph Lateral Scler Frontotemporal Degener. (2017) 18:86-91. doi: 10.1080/21678421.2016.1249486

37. Pinto S, de Carvalho M. Comparison of slow and forced vital capacities on ability to predict survival in ALS. Amyotroph Lateral Scler Frontotemporal Degener. (2017) 18:528-33. doi: 10.1080/21678421.2017.1354995

38. Andrews JA, Meng L, Kulke SF, Rudnicki SA, Wolff AA, Bozik ME, et al. Association between decline in slow vital capacity and respiratory insufficiency, use of assisted ventilation, tracheostomy, or death in patients with amyotrophic lateral sclerosis. JAMA Neurol. (2018) 75:58-64. doi: 10.1001/jamaneurol.2017.3339

39. Sherman MS, Paz HL. Review of respiratory care of the patient with amyotrophic lateral sclerosis. Respiration (1994) 61:61-7. doi: $10.1159 / 000196308$

40. Velasco R, Salachas F, Munerati E, Pradat PF, Lacomblez L, Orvoen EF, et al. Nocturnal oxymetry in patients with amyotrophic lateral sclerosis: role in predicting survival. Rev Neurol. (2002) 158:575-8.

41. Pinto A, de Carvalho M, Evangelista T, Lopes A, Sales Luís ML. Nocturnal pulse oximetry: a new approach to establish the appropriate time for noninvasive ventilation in amyotrophic lateral sclerosis patients. Amyotroph Lateral Scler. (2003) 4:31-5. doi: 10.1080/14660820310006706

42. de Carvalho M, Costa J, Pinto S, Pinto A. Percutaneous nocturnal oximetry in amyotrophic lateral sclerosis: periodic desaturation. Amyotroph Lateral Scler. (2009) 10:154-61. doi: 10.1080/17482960802382305

43. Pinto A, Almeida JP, Pinto S, Pereira J, Oliveira AG, De Carvalho M. Home telemonitoring of non-invasive ventilation decreases healthcare utilisation in a prospective controlled trial of patients with amyotrophic lateral sclerosis. J Neurol Neurosurg Psychiatry (2010) 81:1238-42. doi: 10.1136/jnnp.2010.206680

44. Ogna A, Nardi J, Prigent H, Quera Salva MA, Chaffaut C, Lamothe L, et al. Prognostic value of initial assessment of residual hypoventilation using nocturnal capnography in mechanically ventilated neuromuscular patients: a 5-Year follow-up study. Front Med. (2016) 3:40. doi: 10.3389/fmed.2016.00040

45. Boentert M, Glatz CM, Helmle C, Okegwo AM, Young P. Prevalence of sleep apnoea and capnographic detection of nocturnal hypoventilation in amyotrophic lateral sclerosis. J Neurol Neurosurg Psychiatry (2018) 89:418-24. doi: 10.1136/jnnp-2017-316515

46. Janssens JP, Borel JC, Pépin JL, SomnoNIV Group. Nocturnal monitoring of home non-invasive ventilation: the contribution of simple tools such as pulse oximetry, capnography, built-in ventilator software and autonomic markers of sleep fragmentation. Thorax (2011) 66:438-45. doi: $10.1136 /$ thx.2010.139782

47. Ferguson KA, Strong MJ, Ahmad D, George CF. Sleep disordered breathing in amyotrophic lateral sclerosis. Chest (1996) 110:664-9. doi: 10.1378/chest.110.3.664

48. Arnulf I, Similowski T, Salachas F, Garma L, Mehiri S, Attali V, et al. Sleep disorders and diaphragmatic function in patients with amyotrophic lateral sclerosis. Am J Resp Crit Care Med. (2000) 161:849-56. doi: 10.1164/ajrccm.161.3.9805008

49. Coco DL, Mattaliano P, Spataro R, Mattaliano A, La Bella V. Sleepwake disturbances in patients with amyotrophic lateral sclerosis. $J$ Neurol Neurosurg Psychiatry (2011) 82:899-842. doi: 10.1136/jnnp.2010.2 28007

50. Fitting JW. Sniff nasal inspiratory pressure: simple or too simple? Eur Respir J. (2006) 27:881-3. doi: 10.1183/09031936.06.00007906

51. Lechtzin N. Respiratory effects of amyotrophic lateral sclerosis: problems and solutions. Respir Care (2006) 51:871-81.

52. Caruso P, Albuquerque AL, Santana PV, Cardenas LZ, Ferreira JG, Prina E, et al. Diagnostic methods to assess inspiratory and expiratory muscle strength. J Bras Pneumol. (2015) 41:110-23. doi: 10.1590/\$1806-371320150000 04474

53. ATS/ERS Statement on Respiratory Muscle Testing. Am J Respir Crit Care Med. (2002) 166:518-624. doi: 10.1164/rccm.166.4.518

54. Uldry C, Janssens JP, de Muralt B, Fitting JW. Sniff nasal inspiratory pressure in patients with chronic obstructive pulmonary disease. Eur Respir J. (1997) 10:1292-6. doi: 10.1183/09031936.97.10061292

55. Jackson CE, Rosenfeld J, Moore DH, Bryan WW, Barohn RJ, Wrench M, et al. A preliminary evaluation of a prospective study of pulmonary function studies and symptoms of hypoventilation in ALS/MND patients. J Neurol Sci. (2001) 191:75-8. doi: 10.1016/S0022-510X(01)00617-7

56. Pinto S, Pinto A, de Carvalho M. Do bulbar-onset amyotrophic lateral sclerosis patients have an earlier respiratory involvement than spinal-onset amyotrophic lateral sclerosis patients? Eura Medicoph. (2007) 43:505-9.

57. Morgan RK, McNally S, Alexander M, Conroy R, Hardiman O, Costello RW. Use of sniff nasal inspiratory force to predict survival in amyotrophic lateral sclerosis. Am J Respir Crit Care Med. (2005) 171:269-74. doi: $10.1164 / \mathrm{rccm} .200403-314 \mathrm{OC}$

58. Pinto $S$, de Carvalho M. Sniff nasal inspiratory pressure (SNIP) in amyotrophic lateral sclerosis: Relevance of the methodology for respiratory function evaluation. Clin Neurol Neurosurg. (2018) 171:42-5. doi: 10.1016/j.clineuro.2018.05.011

59. Pinto S, de Carvalho M. Motor responses of the sternocleidomastoid muscle in patients with amyotrophic lateral sclerosis. Muscle Nerve (2008) 38:1312-7. doi: $10.1002 /$ mus.21109

60. Lechtzin N, Shade D, Clawson L, Wiener CM. Supramaximal inflation improves lung compliance in subjects with amyotrophic lateral sclerosis. Chest (2006) 129:1322-9. doi: 10.1378/chest.129.5.1322

61. Mills GH, Kyroussis D, Hamnegard CH, Wragg S, Moxham J, Green M. Unilateral magnetic stimulation of the phrenic nerve. Thorax (1995) 50:1162672. doi: $10.1136 /$ thx. 50.11 .1162

62. Pinto S, Alves P, Pimentel B, Swash M, de Carvalho M. Ultrasound for assessment of diaphragm in ALS. Clin Neurophysiol. (2016) 127:892-7. doi: 10.1016/j.clinph.2015.03.024

63. Fantini R, Mandrioli J, Zona S, Antenora F, Iattoni A, Monelli M, et al. Ultrasound assessment of diaphragmatic function in patients with amyotrophic lateral sclerosis. Respirology (2016) 21:932-8. doi: $10.1111 /$ resp.12759

64. Noda Y, Sekiguchi K, Kohara N, Kanda F, Toda T. Ultrasonographic diaphragm thickness correlates with compound muscle action potential amplitude and forced vital capacity. Muscle Nerve (2016) 53:522-7. doi: $10.1002 /$ mus. 24902

65. Pinto S, Alves $\mathrm{P}$, Swash M, de Carvalho M. Phrenic nerve stimulation is more sensitive than ultrasound measurement of diaphragm thickness in assessing early ALS progression. Neurophysiol Clin. (2017) 47:69-73. doi: 10.1016/j.neucli.2016.08.001

66. Similowski T, Fleury B, Launois S, Cathala HP, Bouche P, Derenne JP. Cervical magnetic stimulation: a new painless method for bilateral phrenic nerve stimulation in conscious humans. J Appl Physiol. (1989) 67:1311-8. doi: 10.1152/jappl.1989.67.4.1311

67. Evangelista T, de Carvalho M, Pinto A, Sales-Luis ML. Phrenic nerve conduction in amyotrophic lateral sclerosis. J Neurol Sci. (1995) 129:35-7. doi: 10.1016/0022-510X(95)00057-9

68. de Carvalho M, Pinto S, Swash M. Diaphragm motor responses to phrenic nerve stimulation in ALS: surface and needle recordings. Clin Neurophysiol. (2018) 129:349-53. doi: 10.1016/j.clinph.2017.11.019 
69. Pinto S, Turkman A, Pinto A, Swash M, de Carvalho M. Predicting respiratory insufficiency in amyotrophic lateral sclerosis: the role of phrenic nerve studies. Clin Neurophysiol. (2009) 120:941-6. doi: 10.1016/j.clinph.2009. 02.170

70. Bach JR. Amyotrophic lateral sclerosis: preditors for prolongation of life by noninvasive respiratory aids. Arch Phys Med Rehabil. (1995) 76:828-32. doi: 10.1016/S0003-9993(95)80547-8

71. Black LF, Hyatt RE. Maximal static respiratory pressures in generalized neuromuscular disease. Am Rev Respir Dis. (1971) 103:641-50.

72. Quanjer P, Lebowitz MD, Gregg I, Miller MR, Pedersen OF. Peak expiratory flow: conclusions and recommendations of a working party of the European Respiratory Society. Eur Respir J. (1997) 24:2S-8S.

73. Suárez AA, Pessolano FA, Monteiro SG, Ferreyra G, Capria ME, Mesa L, et al. Peak flow and peak cough flow in the evaluation of expiratory muscle weakness and bulbar impairment in patients with neuromuscular disease. Am J Phys Med Rehabil. (2002) 81:506-11. doi: 10.1097/00002060-20020700000007

74. Chetta A, Aiello M, Tzani P, Olivieri D. Assessment and monitoring of ventilatory function and cough efficacy in patients with amyotrophic lateral sclerosis. Monaldi Arch Chest Dis. (2007) 67:43-52. doi: $10.4081 /$ monaldi.2007.509
75. Pinto S, Pinto A, Atalaia A, Peralta R, de Carvalho M. Respiratory apraxia in amyotrophic lateral sclerosis. Amyotroph Lateral Scler. (2007) 8:180-4. doi: 10.1080/17482960701249340

76. Pronto-Laborinho AC, Gromicho M, Pereira M, Pinto S, Barros MdA, Swash $\mathrm{M}$, et al. Plasma level of club-cell (CC-16) predicts outcome in amyotrophic lateral sclerosis. Acta Neurol Scand. (2018) 137:233-7. doi: 10.1111/ane.12851

77. Pronto-Laborinho A, Pinto S, Gromicho M, Pereira M, Swash M, de Carvalho M. Interleukin-6 and amyotrophic lateral sclerosis. J Neurol Scii. (2019) 398:50-3. doi: 10.1016/j.jns.2019.01.026

Conflict of Interest Statement: The authors declare that the research was conducted in the absence of any commercial or financial relationships that could be construed as a potential conflict of interest.

Copyright (c) 2019 de Carvalho, Swash and Pinto. This is an open-access article distributed under the terms of the Creative Commons Attribution License (CC BY). The use, distribution or reproduction in other forums is permitted, provided the original author(s) and the copyright owner(s) are credited and that the original publication in this journal is cited, in accordance with accepted academic practice. No use, distribution or reproduction is permitted which does not comply with these terms. 